\title{
Three-Dimensional topological analysis of the experimental and theoretical electron density of a 5-Fluorocytosine/lsoniazid cocrystal
}

\author{
A. B. Wanderley ${ }^{1}$, J. C. Tenorio ${ }^{2}$, I. Camps ${ }^{3}$, C. W. Lehmann ${ }^{4}$, J. Ellena ${ }^{1}$ \\ ${ }^{1}$ Instituto de Física de São Carlos - USP, C.P. 369, 13560-970, São Carlos, SP, Brazil, ${ }^{2}$ Instituto de Química, Universidade Estadual \\ de Campinas - Unicamp, CEP 13083-970, Campinas, SP, Brazil, ${ }^{3}$ Departamento de Física, ICEx/UNIFAL-MG, Alfenas, MG, $37133-$ \\ 840, Brazil, ${ }^{4}$ Max-Planck-Institut für Kohlenforschung, 45470, Mülheim a.d Ruhr, Germany, javiere@ifsc.usp.br
}

Drug-drug cocrystals involve the combination of two or more active pharmaceutical ingredients (API) with their original chemical characteristics maintained without breaking or forming new covalent bonds, thus ensuring its effectiveness.[1] Its pharmaceutical properties are determined by the polarity of functional groups, the electrostatic potential and the available intermolecular interactions, which in turn are characterized by the three-dimensional arrangement and governed by its molecular electronic structure.[2] These molecular electron properties and their relationship with the charge density topology can be analysed by experimental and theoretical studies.

In this manner, the experimental charge density analysis of the pharmaceutical drug-drug cocrystal involving the antimetabolite prodrug 5-Fluorocytosine (5-FC) and the tuberculostatic drug Isoniazid (INH), named 5FC-INH, [3] has been carried out based on the Hansen \& Coppens aspherical multipolar model refinement,[4] using low temperature high resolution X-ray diffraction data $\left(\left(\sin \left(\theta_{\max }\right) / \lambda=1.15\right.\right.$ $\left.\AA^{-1}, 150 \mathrm{~K}\right)$. The experimental model was compared with those derived from corresponding theoretical calculations for solid-state and gas-phase conditions using density functional theory (DFT) methods at the B3LYP $\backslash 6-311++\mathrm{G}^{* *}$ level of theory.[5] The detailed study of the molecular electron density, its corresponding topology and charge distribution were based on the quantum theory of atom in molecules (QTAIM).[6] The charge density distribution and analysis of topological properties revealed that the $\mathrm{C}-\mathrm{F}$ bond may have a transit closed-shell configuration (Fig. 1). This analysis also allowed to verify the charge delocalization due to resonance-assisted hydrogen bond (RAHB) in the formation of the heterosynthon that stabilizes the crystal packing.[7]

(a)

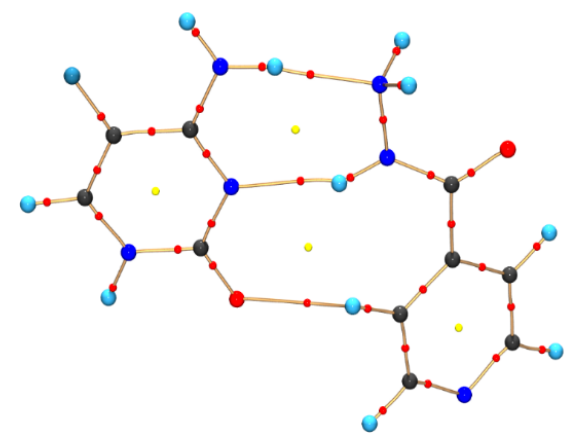

(b)

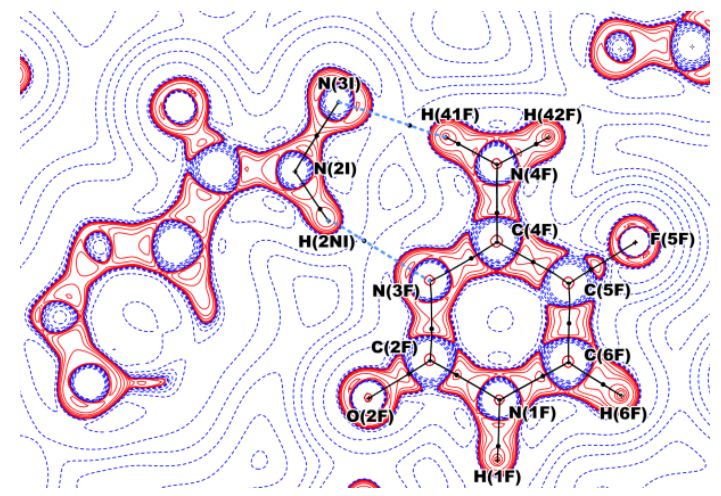

Figure 1. (a) Molecular graph and (b) Contour map of the Laplacian of the electron density of 5FC-INH cocrystal (red lines are positive, violet dotted lines are negative contours)

[1] Zhang, C., Xiong, Y., Jiao, F., Wang, M. and Li, H. (2019). Crystal Growth \& Design. 19, 1471.

[2] Manjula, S., Kalaiarasi, C., Pavan, M. S., Hathwar, V. R. and Kumaradhas, P. (2018). Acta Crystallographica B. 74, 693.

[3] Souza, M. S., Diniz, L. F., Vogt, L., Carvalho Jr. P. S., D’vries, R. F. \& Ellena, J. (2018). Crystal Growth \& Design. 18, 5202.

[4] Hansen, N., Coppens, P. (1978). Acta Crystallographica A. 34, 909.

[5] Wanderley, A. B. (2019). Análise teórica da topologia da densidade de carga eletrônica em sistemas periódicos tridimensionais. Dissertação de Mestrado, Instituto de Física de São Carlos, Universidade de São Paulo, São Carlos. doi:10.11606/D.76.2019.tde-30092019-141547.

[6] Bader, R. F. W. (1994). Atoms in molecules: a quantum theory, edited by, pp. 13-51. New York: Clarendon Press.

[7] Gilli, G., Bellucci, F., Ferretti, V. and Bertolasi, V. (1989). Journal of the American Chemical Society. 111, 1023.

Keywords: electronic charge density; drug-drug cocrystals; multipolar refinement; atom in molecules; topology.

This study was financed in part by the Coordenação de Aperfeiçoamento de Pessoal de Nivel Superior - Brasil (CAPES) - Financed Code 001 as well as Fundação de Amparo à Pesquisa do Estado de São Paulo (FAPESP), process number: 2016/08823-4.

Acta Cryst. (2021), A77, C909 